\title{
ESTUDIOS SOBRE LAS RUBIÁCEAS DE MÉXICO, L Una Guettarda nueva (Guettardeae, Rubiaceae) en Oaxaca
}

\author{
A. Borhidi ${ }^{1}$, K. Velasco-Gutierrez ${ }^{2}$ y V. Vásquez-Martínez ${ }^{3}$ \\ ${ }^{1}$ Departamento de Fitotaxonomía y Geobotánica, Instituto de Biología \\ Universidad de Pécs, H-7624 Pécs, Ifjúság útja 6, Hungría; E-mail: borhidi@gamma.ttk.pte.hu \\ ${ }^{2}$ Sociedad para el Estudio de los Recursos Bióticos de Oaxaca A. C., México \\ E-mail:keniave@gmail.com \\ ${ }^{3}$ Unión de Comunidades Indígenas de la Zona Norte del Istmo A. C., México \\ E-mail:tum.ujx@gmail.com
}

(Received 4 November, 2014; Accepted 15 December, 2014)

The new Guettarda species of Oaxaca (Mexico) is related to G. foliacea Standl. of a distribution from Tabasco and Chiapas to Panama, but differs by having long acuminate and falcate leaves with lineolate quaternary nerves on the abaxial surface, inflorescences with very short ovate and glabrous bracteoles and much shorter flowers with $8-9 \mathrm{~mm}$ long corolla tube.

Key words: Guettarda, Mexico, new, Oaxaca, Rubiaceae, selva alta perennifolia

\section{Guettarda elongata Borhidi, K. Velasco-Gutierrez et V. Vásquez- Martínez, spec. nova, hoc loco}

(Fig. 1)

Tipo: México, Oaxaca, Juchitán, Ejido Zacatal, paraje Mëëtyunkojpk., San Juan Guichicovi. Vegetación secundaria, selva alta con "Corpo", "Chancarro", "Diez hojas", "Cañafistula”, a orilla de la carretera. Coord.: $16^{\circ} 57^{\prime} 9.4^{\prime \prime} \mathrm{N}, 95^{\circ} 12^{\prime} 35.8^{\prime \prime} \mathrm{W}$, alt. $634 \mathrm{~m}$ snm. Col.: Victorino Vásquez Martínez 153, Kenia Roque, Cleofas, Alberto y Carlos, 05.07.2014. Holotipo: MEXU.

Frutex vel arbor parva, $2.5 \mathrm{~m}$ alta, rami cylindracei, cinerascentes, longitudinaliter profunde striati, horizontaliter fissurati, glabri; rami laterales ascendentes, arcuati, principali equaliter longi, ramuli angulati, pilis longisque strigosis, albis adpresse hirsuti. Stipulae elongato-lanceolatae, subulatae et apice mucronatae, usque ad $10 \mathrm{~mm}$ longae, mucrone 2-5 mm longo, utrinque adpresse strigosae. Folia apice ramorum ad nodos terminales et subterminales conferta, elliptica vel elongato-elliptica, 2-13 cm longa et $0.8-4.5 \mathrm{~cm}$ lata, apice longe acuminata et apiculata regulariter falcata, acumine usque ad $2 \mathrm{~cm}$ longa et $1.5 \mathrm{~mm}$ longe mucronata, basi longe at- 
tenuata cuneata et in petiolo 5-12 mm longo et dense strigoso-hirsuto decurrentia; limbus folii papyraceus, supra viridis in sicco flavescens, subtus pallidior, supra pilis usque ad $1.5 \mathrm{~mm}$ longis sparse pilosus subtus et ad nervos densiore puberulus nervo centrali supra prominulo, subtus prominente, lateralibus utroque latere 5-8, apicem versus arcuatis, sine contacto usque ad marginem excurrentibus, supra prominulis, subtus prominentibus, utrinque adpresse strigulosis, tertiarii reticulati, quaternarii venis parallelibus dense dispositis lineolati; nervatura utrinque bene visibilis. Inflorescentiae axillares, 1 per axillam; pedunculi 10-25 mm longi, pilis antrorsis dense albo-hirsuti. Cyma simplicis cum flore uno centrali et 2 ramulis brevibus 2-3-floribus suffultus rarissime adest, cymae regulariter compositae 3-varicatae, ramulis lateralibus 5-9-floris et florem centralem ramis 5-7 floris vel inflorescentia partiale paniculata multiflora substitutum, rariter cum ramis lateralibus cymae divaricatis inflorescentia 5-radialem 15-45-floram producta; ramuli laterales cymae floribus sessilibus capitatae vel subcapitatae. Bracteae bracteolaeque ovatae, rotundatae, 0.5 mm longae, glabrae. Hypanthium obovatum, albo-hirsutum vel villosum, usque ad 1-2 mm longum; tubus calycis 1-1.5 mm longus, extus pilosus vel glabrescens, intus glaber, apice truncatus 4 denticulis retundatis, $0.2 \mathrm{~mm}$ longis suffultus vel irregulariter undulatus. Corolla 9-10 mm longa, lutea, in sicco rubello-viridis; tubus 8-9 mm longus, latis parallelibus, basi 0.7-0.8 mm, fauce 1-1.5 mm latus, extus pilis antrorsis sericeo puberulus intus sub medio pilosulus, fauce glabro; lobi corollini 4, 1-2 mm longi et lati, triangular-ovati, extus sericei, intus glabri. Stamina 4, in tubo corollino sub fauce inserta, filamenta $0.5 \mathrm{~mm}$ longa, glabra, antherae dorsifixae, lineares, $2 \mathrm{~mm}$ longae et $0.2 \mathrm{~mm}$ latae, basi longe sagittatae appendicibus linearibus et acutis $0.5 \mathrm{~mm}$ longis, apicibus fauce vix apparentibus. Pistillum breve, in tubo corollino sub medio insertum; stylus $2 \mathrm{~mm}$ longus, glaber, stigma bilobatum, $0.5 \mathrm{~mm}$ longum, ramulis inaequilongis. Fructus ignotus.

Arbusto de $2.5 \mathrm{~m}$ de alto, ramas cilíndricas, grisáceas, longitudinalmente profundo-estriadas y horizontalmente fisuradas, glabras, ramas laterales ascendentes de igual largo que el tallo principal; ramitas angulosas con pelos estrigosos y largos blancos apretado hirsutas. Estípulas alargado lanceoladas, subuladas y mucronadas en el ápice, rojizas, de hasta $10 \mathrm{~mm}$ de largo, con un mucrón de 2-5 mm de largo, apretado estrigosas en ambas caras. Hojas agrupadas en los nudos terminales y subterminales de las ramas, elípticas o alargado elípticas, de $2-13 \mathrm{~cm}$ de largo y $0.8-4.5 \mathrm{~cm}$ de ancho, largamente acuminadas, apiculadas y regularmente falcadas en el ápice con el acumen de hasta $2 \mathrm{~cm}$ de largo y mucronadas con un mucrón de hasta $1.5 \mathrm{~mm}$ de largo; la base largamente atenuada, cuneada y decurrente en el pecíolo de 5-12 $\mathrm{mm}$ de largo, densamente estrigoso-hirsuto; el limbo de las hojas papiráceas, verdes en el haz, amarillento cuando seco, más pálido en el envés, el haz con pelos largos de hasta $1.5 \mathrm{~mm}$ de largo esparcidamente peloso, más densamente en 


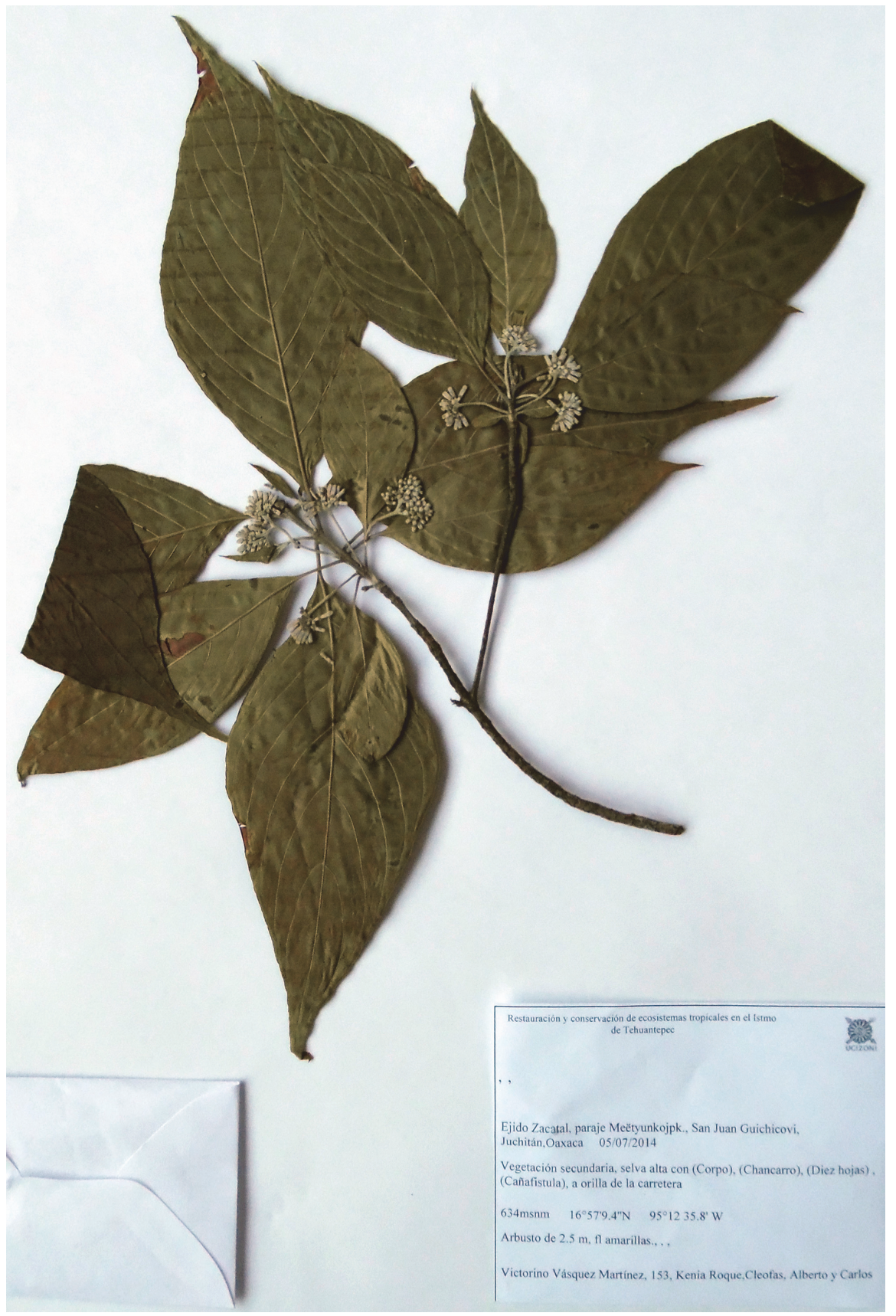

Fig. 1. Holotipo de la Guettarda elongata Borhidi, K. Velasco-Gutierrez et V. Vásquez-Martínez en MEXU (Foto: A. Borhidi) 
los nervios y en el envés; nervio medio promínulo en el haz, prominente en el envés, los secundarios de 5-8 pares, arqueados hacia el ápice y salen hasta el margen sin conectarse, promínulos en el haz, prominentes en el envés, apretado estrigilosos en ambas caras; los nervios terciarios reticulados, los cuaternarios lineolados con venas paralelas densamente dispuestas; la nervadura bien visible en ambas caras. Inflorescencias axilares, cada axila con una inflorescencia; pedúnculos de 10-25 mm de largo, densamente blanco-hirsutos con pelos antrorsos. La cima sencilla con una flor central y 2 ramas cortas de 2-3 flores es muy rara, las cimas generalmente son varias veces compuestas, 3-varicadas, cuando las ramas laterales tienen 5-9 flores y la flor central esta sustituida por una rama de 5-7 flores, una micro-panicula de muchas flores, a veces las ramas laterales divaricadas también formando una inflorescencia 5-radial con 15-45 flores. Las ramas cortas acabezueladas, flores sésiles. Brácteas y bractéolas ovales, redondeadas, de $0.5 \mathrm{~mm}$ de largo, glabras; hipanto obovado, blanco-hirsuto a velloso, de 1-2 mm de largo; tubo del cáliz de 1-1.5 $\mathrm{mm}$ de largo, peloso a glabrescente por fuera, glabro por dentro, truncado en el ápice con 4 dentículos redondeados, de $0.2 \mathrm{~mm}$ de largo o irregularmente undulado. Corola de 9-10 mm de largo, amarilla, rojizo-verde en seco; tubo de $8-9 \mathrm{~mm}$ de largo, con lados paralelos, de $0.7-0.8 \mathrm{~mm}$ de ancho en la base y 1-1.5 mm de ancho en la garganta, seríceo-pubérula por fuera con pelos antrorsos, pelosítos por dentro en la mitad inferior, la garganta glabra; lóbulos 4, de 1-2 mm de largo y ancho, triangular-ovados, seríceos por fuera, glabros por dentro. Estambres 4, insertos en el tubo corolino $2 \mathrm{~mm}$ debajo del orificio de la garganta, filamentos de $0.5 \mathrm{~mm}$ de largo, glabros, anteras dorsifijas, lineares, de $2 \mathrm{~mm}$ de largo y $0.2 \mathrm{~mm}$ de ancho, largamente flechadas en la base, con apéndices lineares y agudos de $0.5 \mathrm{~mm}$ de largo, las puntas apicales apenas aparentes en la garganta. Pistilo corto, inserto; estilo de $2 \mathrm{~mm}$ de largo, glabro, estigma 2-lobulado, de $0.5 \mathrm{~mm}$ de largo, ramitas inequilargas. Fruto desconocido.

Etimología: El epiteto específico de la especie nueva tiene origen latino elongatus, $-a,-u m$, que significa alargado refiriendose a la forma y ápice de la hoja.

Afín a Guettarda foliacea Standl. distribuida de Tabasco y Chiapas hasta Panamá por tener estípulas de hasta $10 \mathrm{~mm}$ de largo, hojas alargadas, de 4-15 por 2-9 cm, agudas, en el ápice, obtusas a redondeadas en la base con nervios laterales 4-8-pares, pero G. elongata de Oaxaca difiere de ella en tener hojas largamente acuminadas y falcadas en el ápice; venas cuaternarias lineoladas en el envés. Inflorescencias con brácteas y bractéolas ovadas de $0.5 \mathrm{~mm}$ de largo, glabras, tubo corolino 8-9 mm de largo, mientras G. foliacea tiene hojas obtusas, agudas a brevemente acuminadas en el ápice, venas cuaternarias reticuladas en el envés, inflorescencias con brácteas de 3-8 mm de largo presen- 
tes en todos los ejes, y flores notablemente más grandes con tubo corolino de 12-18 mm de largo.

Nota: En la Flora Mesoamericana Guettarda foliacea no esta reportada de México, aunque una colecta de Tabasco y otra de Chiapas representan indudablemente esta especie.

Agradecimientos - La colecta fue realizada en el marco del proyecto: Restauración y conservación de ecosistemas tropicales en el Istmo de Tehuantepec ejecutado por la Unión de Comunidades Indígenas de la Zona Norte del Itsmo AC (UCIZONI). Los autores expresan sus agradecimientos al Ejido El Zacatal, San Juan Guichicovi, y a las Autoridades Agrarias, a los jóvenes Juan Carlos José y Kenia Roque por su apoyo en campo; al Coordinador y a la Mesa Directiva de la UCIZONI; al Dr. Gerardo Adolfo Salazar, jefe del Departamento de Botánica, del Instituto de Biologia de la UNAM; al Dr. David Sebastian Gernandt, jefe del Herbario Nacional de México (MEXU) y al Biol. Mauricio Mora Jarvio, por su apoyo en crear condiciones favorables para este trabajo.

\section{LITERATURA CONSULTADA}

Borhidi, A. (2012): Rubiáceas de México. Segunda y ampliada edición. - Akadémiai Kiadó, Budapest, 610 pp.

Borhidi, A. y Reyes-García, A. (2007): Estudios sobre Rubiáceas Mexicanas XV. Una especie nueva del género Guettarda de Chiapas. - Acta Bot. Hung. 49: 59-61. doi: 10.1556/ ABot.49.2007.1-2.6

Ramos, C. H. y Borhidi, A. (2013): Una nueva especie del género Guettarda (Rubiaceae) en México. - Acta Bot. Hung. 55: 217-221. doi: 10.1556/ABot.55.2013.3-4.2

Taylor, C. M. y Lorence, D. H. (2012): Guettarda L. - In: Davidse, G., Sousa, M., Knapp, S. y Chiang, F. (eds gen.): Flora Mesoamérica. IV(2): Rubiaceae, Cordiaceae, Boraginaceae, Lamiaceae. Universidad Nacional Autónoma de México, Missouri Botanical Garden, The Natural History Museum (London), pp. 107-113. 